\title{
PENGARUH MATRIKS PEKTIN DAN HPMC K15M TERHADAP DAYA MENGAPUNG DAN MENGEMBANG SERTA DISOLUSI PADA TABLET FLOATING VERAPAMIL HCI DENGAN METODE FACTORIAL DESIGN
}

\section{THE EFFECT OF PECTIN AND HPMC K15 M MATRIX ON FLOATATION BEHAVIOUR, SWELLING AND DISOLUTION OF VERAPAMIL HCL FLOATING TABLET USING FACTORIAL DESIGN METHOD}

\author{
Valentina Ayuk Armadani ${ }^{1}$, Siti Aisiyah ${ }^{2}$, Ilham Kuncahyo ${ }^{3}$ \\ mynanda.ais@gmail.com \\ ${ }^{1}$ S1 Farmasi, Fakultas Farmasi, Universitas Setia Budi,Surakarta \\ 2Laboratorium Instrumentasi, S1 Farmasi, Fakultas Farmasi, Universitas Setia Budi,Surakarta \\ ${ }^{3}$ Laboratorium Teknologi Farmasi, S1 Farmasi, Fakultas Farmasi, Universitas Setia Budi, Surakarta
}

\begin{abstract}
Abstrak
Verapamil $\mathrm{HCl}$ merupakan penghambat kanal $\mathrm{Ca}^{2+}$ untuk terapi hipertensi dan angina pectoris. Verapamil $\mathrm{HCl}$ memiliki bioavabilitas $10-$ $20 \%$ dan waktu paruh 4 jam sehingga dapat dibuat sediaan gastroretentive untuk mempertahankan kadar terapi obat. Penelitian ini bertujuan mengetahui pengaruh matriks pektin dan HPMC K15M terhadap kemampuan mengapung, mengembang dan pelepasan obat pada tablet floating verapamil $\mathrm{HCl}$.

Penelitian ini menggunakan empat formula variasi konsentrasi matriks pektin dan HPMC K15M dengan metode kempa langsung kemudian dilakukan pengujian terhadap sifat fisik serbuk dan tablet. Pengaruh dan interaksi antara pektin dan HPMC K15M ditentukan dengan metode factorial design menggunakan software Design Expert.

Matriks pektin dan HPMC K15M memberikan pengaruh terhadap kemampuan mengapung, mengembang dan pelepasan obat dari tablet floating verapamil $\mathrm{HCl}$. HPMC K15M berpengaruh dominan terhadap floating lag time yang lebih cepat dan floating time yang lebih lama. Peningkatan HPMC K15M dan pektin menurunkan jumlah pelepasan di awal dan kecepatan pelepasan obat, serta meningkatkan kemampuan mengembang. Kombinasi pektin dan HPMC K15 M $(1,5: 1)$ mempunyai floating lag time cepat, floating time lama, dan kemampuan mengembang paling besar serta mengikuti orde nol.
\end{abstract}

Kata kunci : floating, verapamil HCl, pektin, HPMC K15M

\begin{abstract}
Verapamil $\mathrm{HCl}$ is Calcium Channel blocker (CCB) used to treat hypertension and angina pectoris. Verapamil $\mathrm{HCl}$ has a bioavailability of $10-20 \%$ and half-life of 4 hours so it can be made gastroretentive preparations for defending drug therapy concentration. This study was purposed to know the effect of pectin and HPMC K15M on floatation behaviour, swelling and drug released of verapamil $\mathrm{HCl}$ floating tablet.

This study used four varying matrix concentrations of pectin and HPMC K15M with direct compression method then evaluated physical properties of powders and tablets. Effects and interactions between pectin and HPMC K15M were given by factorial design method using software Design Expert ${ }^{\circledR}$.
\end{abstract}


Matrix of pectin and HPMC K15M gave effects to floatation behaviour, swelling and drud released of verapamil $\mathrm{HCl}$ floating tablet. HPMC K15M was dominant influenced about decreased floating lag time and increased floating time. Increased of HPMC K15M and pectin could be decreased initial burst and drug released rate but increased swelling. Pectin and HPMC K15M (1,5:1) combination had the fastest of floating lag time, the longest time of floating time, the greatest of swelling and followed zero order.

Keyword : floating, verapamil HCl, pectin, HPMC K15M 


\section{Pendahuluan}

Verapamil $\mathrm{HCl}$ merupakan penghambat kanal $\mathrm{Ca}^{2+}$ yang digunakan untuk pengobatan angina pectoris, hipertensi, dan takiaritmia supraventrikuler. Verapamil $\mathrm{HCl}$ memiliki bioavabilitas rendah (10-20\%) dan waktu paruh hanya 4 jam sehingga pemberian dosis sering dilakukan. Verapamil $\mathrm{HCl}$ larut dalam medium air. Karakteristik dari verapamil $\mathrm{HCl}$ ini sesuai untuk didesain menjadi sediaan tablet floating. Tablet floating dirancang untuk mempertahankan kadar terapi obat dalam darah dalam jangka waktu lama (Kilicarslan dan Tamer, 2003).

FDDS (Floating Drug Delivery Systems) merupakan sistem yang memiliki densitas bulk lebih rendah daripada cairan lambung sehingga dapat mengapung dalam periode waktu yang lama tanpa dipengaruhi oleh kecepatan pengosongan lambung. Proses pengapungan meliputi pelepasan obat perlahan dan berkelanjutan kemudian setelah obat dilepaskan semua sisa sistem harus dapat dikosongkan dari lambung. FDDS ada 2 macam yaitu noneffervescent systems dan effervescent systems (Sravya et al. 2012).

HPMC K15M merupakan matriks hidrofilik yang mampu mengembang membentuk lapisan gel dan menahan pelepasan obat. Pembentukan lapisan gel berpengaruh pada pelepasan obat dari matriks HPMC (Siepmenn dan Peppas, 2012). Kelemahan yang lain yaitu terjadi initial burst release dimana pelepasan obat di awal lebih tinggi sehingga pelepasan obat menjadi tidak konstan (Abed et al. 2011). Pektin merupakan polimer hidrofilik yang mengalami erosi dan pembengkakan serta membentuk lapisan gel ketika kontak dengan media air. Kinetika pelepasan obat dari matriks pektin ini melalui difusi dan erosi. Kemampuan mengembang pektin dipengaruhi oleh $\mathrm{pH}$, dimana pada media asam, pektin memiliki kemampuan mengembang lebih tinggi (Sriamornsak et al.
2007). Pektin high methoxy dapat digunakan untuk pembuatan tablet kempa langsung yang dikombinasikan dengan HPMC (Kadajji, 2011).

Pengaruh dan interaksi antara pektin dan HPMC dapat ditentukan dengan metode factorial design. Metode factorial design dapat menentukan banyaknya percobaan oleh banyaknya level dan faktor yang digunakan, untuk 2 faktor dengan 2 level digunakan percobaan sebanyak $2^{\mathrm{n}}$, dimana 2 adalah banyak level yang digunakan, dan $\mathrm{n}$ adalah banyak faktor yang digunakan. Keuntungan dari penggunaan metode ini yaitu semua efek dan interaksinya bersifat independen sehingga tidak dipengaruhi faktor-faktor lain yang bersifat kualitatif dan kuantitatif (Bolton \& Bon 2004).

Hasil penelitian ini diharapkan dapat diperoleh sediaan tablet floating verapamil $\mathrm{HCl}$ dengan pelepasan obat mengikuti kinetika orde nol sehingga dapat meningkatkan efektivitas dan bioavailabilitas dari verapamil $\mathrm{HCl}$, selain itu perlu dilakukan optimasi untuk mengetahui formula optimum dari kombinasi matriks pektin dan HPMC K15M pada tablet floating verapamil $\mathrm{HCl}$ dengan metode factorial design.

\section{Metode Penelitian}

Alat

Mesin tablet Single Punch(TDP-01 Shanghai), timbangan analitik (Ohaus PA213 ketelitian $1 \mathrm{mg}$ ), friabilator (Erweka GMB-H), hardness tester (Stokes Mosanto dan Gaoming YD-01), Spekrofotometer UV-VIS, dissolution tester (Electrolab TDT-08L).

\section{Bahan}

Verapamil HCl (Recordati, Itali), HMPC K15M (Dexa Medika, Indonesia), pektin (Brataco, Indonesia), Avicel PH 102 (Interbat, Indonesia), natrium bikarbonat (Brataco, Indonesia), asam sitrat (Brataco, Indonesia), talk (Brataco, Indonesia), magnesium stearate (Brataco, Indonesia), $\mathrm{HCl}$ (Merk). 
Tabel I. Formula tablet floating verapamil HCl menggunakan kombinasi matriks pektin dan HPMC K15M

\begin{tabular}{|c|c|c|c|c|}
\hline \multirow[t]{2}{*}{ Bahan } & \multirow[b]{2}{*}{ F1 } & \multicolumn{2}{|c|}{ Komposisi } & \multirow[b]{2}{*}{ F4 } \\
\hline & & F2 & F3 & \\
\hline Verapamil HCl & 180 & 180 & 180 & 180 \\
\hline Pektin & 100 & 150 & 100 & 150 \\
\hline HPMC K15M & 50 & 50 & 100 & 100 \\
\hline $\mathrm{Na}$ bikarbonat & 70 & 70 & 70 & 70 \\
\hline Asam sitrat & 30 & 30 & 30 & 30 \\
\hline Avicel PH 102 & 158 & 108 & 108 & 58 \\
\hline Mg Stearat & 6 & 6 & 6 & 6 \\
\hline Talkum & 6 & 6 & 6 & 6 \\
\hline Bobot total & 600 & 600 & 600 & 600 \\
\hline
\end{tabular}

Keterangan :

Formula $1: 100 \mathrm{mg}$ Pektin (aras rendah) dan $50 \mathrm{mg}$ HPMC K15M (aras rendah)

Formula 2: $150 \mathrm{mg}$ Pektin (aras tinggi) dan $50 \mathrm{mg}$ HPMC K15M (aras rendah)

Formula 3 : $100 \mathrm{mg}$ Pektin (aras rendah) dan $100 \mathrm{mg}$ HPMC K15M (aras tinggi)

Formula 4 : $150 \mathrm{mg}$ Pektin (aras tiggi) dan $100 \mathrm{mg}$ HPMC K15M (aras tinggi)

\section{Tahapan Penelitian}

\section{Pembuatan kurva kalibrasi}

Larutan induk verapamil $\mathrm{HCl}$ dibuat seri konsentrasi 20 ppm, 30 ppm, 40 ppm, 50 ppm, 70 ppm dan $100 \mathrm{ppm}$. Seri konsentrasi diukur serapannya dengan spektrofotometer pada panjang gelombang $278 \mathrm{~nm}$. Serapan diperoleh dibuat persamaan regresi linear antara kadar verapamil $\mathrm{HCl}$ dan serapannya.

\section{Pembuatan tablet}

Verapamil $\mathrm{HCl}$ sebagai model obat dicampur dengan kombinasi polimer HPMC K15M/pektin, Avicel PH 102, dan Na bikarbonat selama 15 menit kemudian ditamabahkan asam sitrat sampai homogen. Campuran serbuk tersebut ditambah dengan campuran bahan pelicin $\mathrm{Mg}$ stearat dan talkum dicampur selama 5 menit kemudian dikempa langsung dengan alat kempa tablet single punch. Sebelum dilakukan pencampuran masing-masing natrium bikarbonat dan asam sitrat diayak dulu dengan ayakan Mesh 40 dan dioven suhu $50^{\circ} \mathrm{C}$ selama 15 menit. Sebaiknya pembuatan dilakukan pada ruangan suhu dingin dan kelembaban ruangan yang terkendali $(<30 \%)$.

\section{Pemeriksaan sifat fisik massa tablet}

Pemeriksaan sifat fisik massa tablet dilakukan dengan memeriksa waktu alir dan sudut diam menggunakan metode corong.

\section{Pemeriksaan sifat fisik tablet}

Pemeriksaan sifat fisik tablet dilakukan dengan memeriksa ketebalan tablet menggunakan jangka sorong (ketelitian 0,02 mm) (10 tablet), kekerasan dengan Stokes Mosanto hardness tester (10 tablet), kerapuhan dengan friability tester (20 tablet), dan kandungan obat (10 tablet) secara spektrofotometri.

\section{Karakteristik kemampuan mengapung}

Floating lag time (FLT) dan floating time (FT) dari tablet ditentukan menggunakan $100 \mathrm{ml} \mathrm{HCl}$ $0,1 \mathrm{~N}$ dalam gelas beaker. Waktu yang diperlukan untuk tablet mengapung secara konstan disebut dengan floating lag time dan lama waktu mengapung disebut dengan floating time. Uji swelling dilakukan dengan cara mengukur penambahan volume tablet tiap menit ke 30, 60, 90, 120, 150, 180, 210, 240, 300 dan 360 dalam $200 \mathrm{ml}$ media $\mathrm{HCl} 0,1 \mathrm{~N}$.

\section{Pelepasan obat secara in vitro}

Pelepasan obat ditentukan dengan dissolution tester apparatus II (paddle) digunakan sinker untuk mencegah tablet mengapung, $900 \mathrm{ml}$ $\mathrm{HCl} 0,1 \mathrm{~N}$ sebagai medium dengan suhu $37 \pm 0,5 \mathrm{oC}$ pada kecepatan putaran $50 \mathrm{rpm}$ selama 6 jam. Sampel diambil sebanyak $10 \mathrm{ml}$ pada menit ke-15, 30, 60, 90, 120, 180, 240, 300, dan 360 dan diganti dengan medium yang baru. Semua sampel dianalisa secara spektrofotometer UV pada panjang gelombang maksimum verapamil $\mathrm{HCl}(278 \mathrm{~nm})$.

\section{Analisa hasil}

Penentukan nilai Q (\% terdisolusi) dan nilai DE (\%)selama menit 60 dan menit 360. Kinetika pelepasan obat ditentukan dengan hubungan antara: waktu dengan persentase obat yang terlarut (orde nol), akar waktu dengan persentase obat yang 
Pengaruh Matriks Pektin Dan Hpmc K15m Terhadap Daya Mengapung Dan Mengembang Serta Disolusi Pada Tablet Floating Verapamil Hcl Dengan Metode Factorial Design

terlarut (higuchi), waktu dengan In fraksi obat yang tidak larut (orde satu) dan log waktu dengan log persentase obat yang terlarut (Korsmeyer-Peppas). Data dianalisis dengan metode factorial design menggunakan program "Design Expert 7.1.5" untuk melihat pengaruh dan interaksi pektin dan HPMC K15M pada masing-masing formula. 


\section{Hasil dan Pembahasan}

\section{Kurva kalibrasi}

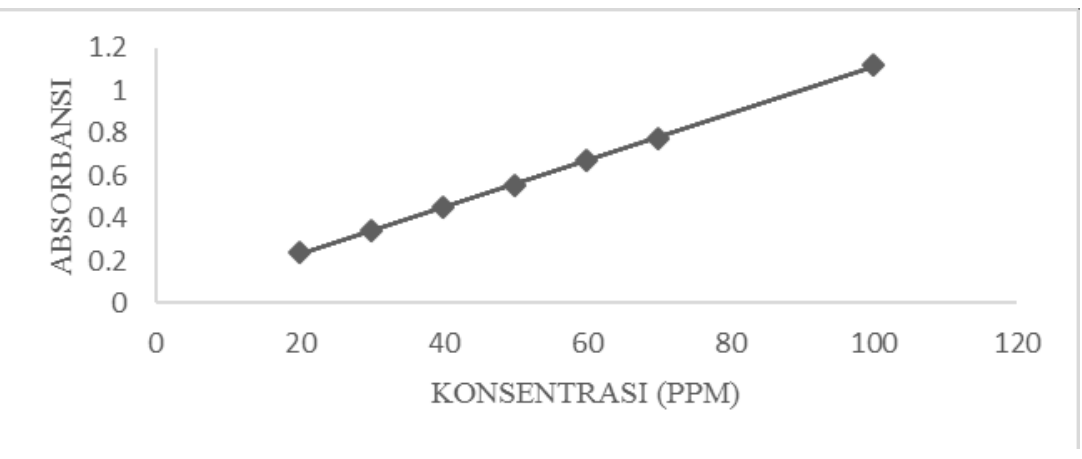

Gambar 1. Kurva kalibrasi verapamil $\mathrm{HCl}$

Plot antara konsentrasi dan serapan menghasilkan persamaan regresi linier yaitu y $=0,011 \mathrm{x}+0,0144$, dimana $\mathrm{x}$ merupakan konsentrasi verapamil $\mathrm{HCl}$ dan y merupakan serapan. Koefisien korelasi yang diperoleh dari persamaan adalah sebesar 0,9996. Pesamaan regresi linear yang diperoleh

Tabel II. Hasil pemeriksaan sifat fisik serbuk

\begin{tabular}{lcccc}
\hline Parameter & \multicolumn{4}{c}{ Formula } \\
& \multicolumn{5}{c}{ F1 } & F2 & F3 & F4 \\
Waktu alir (detik) & $9,96 \pm 0,13$ & $11,38 \pm 0,13$ & $11,00 \pm 0,27$ & $11,56 \pm 0,45$ \\
Sudut diam $\left({ }^{\circ}\right)$ & $29,79 \pm 0,67$ & $30,20 \pm 0,02$ & $30,69 \pm 0,12$ & $31,83 \pm 0,25$ \\
\hline
\end{tabular}

Tabel III. Hasil pemeriksaan sifat fisik tablet

\begin{tabular}{lcccc}
\hline \multirow{2}{*}{ Parameter } & \multicolumn{4}{c}{ Formula } \\
\cline { 2 - 5 } & F1 & F2 & F3 & F4 \\
\hline Keseragaman bobot (mg) & $605,40 \pm 4,43$ & $604,7 \pm 4,33$ & $605,05 \pm 5.37$ & $604,80 \pm 2,82$ \\
\hline Kekerasan (kg) & $15,72 \pm 0,2$ & $14,7 \pm 0,51$ & $14,37 \pm 0,62$ & $13,05 \pm 0,77$ \\
\hline Kerapuhan (\%) & $0,869 \pm 0,09$ & $0,901 \pm 0,09$ & $0,95 \pm 0,04$ & $0,76 \pm 0,08$ \\
\hline Tebal tablet (cm) & $0,40 \pm 0,03$ & $0,39 \pm 0,01$ & $0,38 \pm 0,01$ & $0,38 \pm 0,003$ \\
\hline Floating lag time (detik) & $33,33 \pm 2,58$ & $33,67 \pm 8,091$ & $21,50 \pm 1,38$ & $24,83 \pm 2,229$ \\
\hline Floating time (jam) & $7,00 \pm 1,05$ & $21,67 \pm 3,67$ & $24 \pm 0$ & $24,17 \pm 0,41$ \\
\hline Indeks Swelling (\%) & $13,76 \pm 8,997$ & $52,291 \pm 6,96$ & $100,88 \pm 35,41$ & $127,65 \pm 45,0$ \\
\hline Penetapan kadar (mg) & $178,446 \pm 4,16$ & $179,60 \pm 9,572$ & $180,01 \pm 2,28$ & $179,86 \pm 2,44$ \\
\hline Keseragaman kandungan(\%) & $103,35 \pm 5,19$ & $101,58 \pm 5,39$ & $100,28 \pm 5,16$ & $99,89 \pm 5,66$ \\
\hline
\end{tabular}

\section{Sifat fisik massa tablet}

Massa tablet dinyatakan memiliki waktu alir yang baik jika tidak lebih dari 10 detik/100gram (Siregar \& Wikarsa 2011). Massa tablet dengan sudut diam $<30^{\circ}$ memenuhi parameter linearitas, Persamaan regresi linear yang memenuhi linearitas dengan nilai koefisien determinasi $\left(\mathrm{R}^{2}\right)$ lebih dari 0,786 untuk 7 seri konsentrasi yang berbeda (Gandjar \& Rohman 2012).

Sudut diam $\left(^{\circ}\right.$ $29,79 \pm 0,67$ $30,20 \pm 0,02$ $30,69 \pm 0,12$ 


\section{Kemampuan mengapung}

Hasil pemeriksaan semua tablet floating verapamil $\mathrm{HCl}$ mempunyai floating lag time kurang dari 1 menit (21 sampai 33 detik), dilakukan dengan pendekatan secara factorial design didapatkan persamaan $\mathrm{Y}=28,58$ $+0,67$ A - 5,42 B + 1,00 AB. Hasil koefisien regresi menunjukkan bahwa peningkatan faktor pektin $(0,67)$ dapat memberikan pengaruh pada peningkatan floating lag time.
Interaksi antara pektin dan HPMC K15M dapat memberikan pengaruh lebih besar pada peningkatan floating lag time $(1,00)$ daripada faktor pektin. Faktor HPMC K15M $(-5,42)$ memberikan pengaruh pada penurunan floating lag time. Perbedaan BJ antara kedua faktor dapat mempengaruhi cepat lambatnya tablet mengapung. BJ pektin lebih tinggi daripada BJ HPMC K15M sehingga semakin tinggi jumlah pektin maka semakin sulit tablet untuk mengapung.

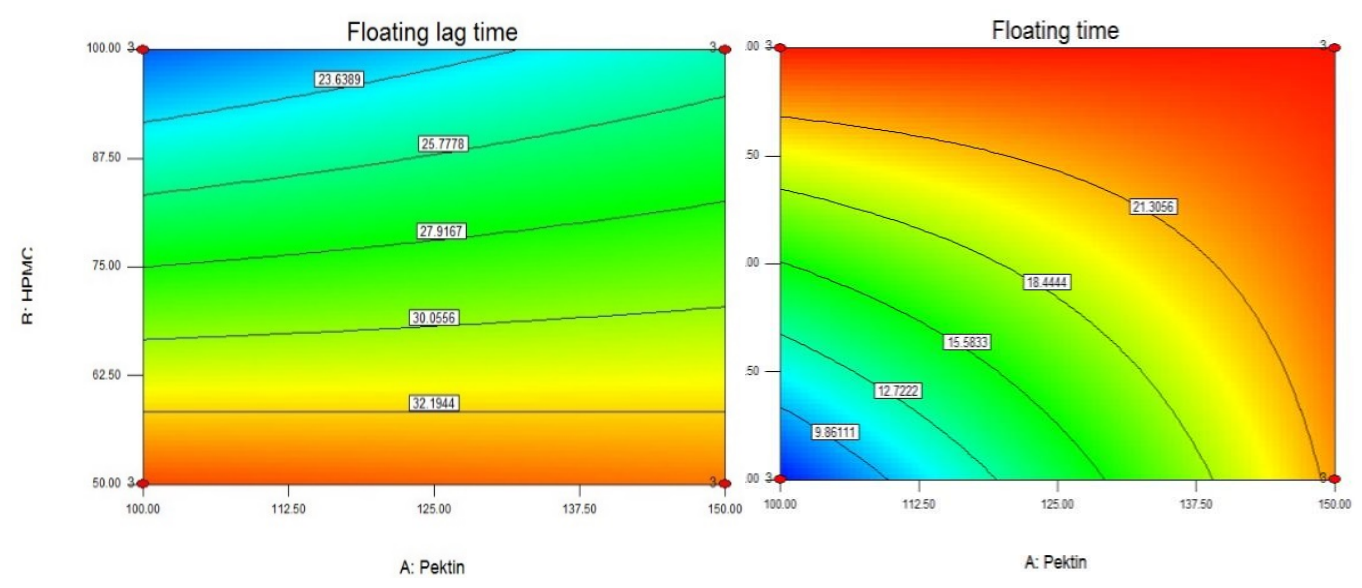

Gambar 2. Contour plot kemampuan mengapung

Floating time yang tinggi diasumsikan bahwa tablet lebih lama tinggal di lambung sehingga obat diabsorbsi lebih besar di lambung dan meningkatkan bioavabilitasnya. Hasil pemeriksaan tablet floating verapamil $\mathrm{HCl}$ menunjukkan floating time sekitar 7 sampai 24 jam dengan persamaan $\mathrm{Y}=19,21+3,71 \mathrm{~A}+4,87 \mathrm{~B}-$ 3,63 AB. Hasil koefisien regresi menunjukkan bahwa faktor HPMC K15M $(4,87)$ memberikan pengaruh pada peningkatan floating time lebih besar daripada faktor pektin (3,71). Interaksi kedua faktor memberikan pengaruh pada penurunan floating time $(-3,63)$. Adanya perbedaan sifat antara matriks pektin dan HPMC K15M yang menyebabkan interaksi kedua faktor tersebut menurunkan floating time. Pektin memiliki sifat lebih mudah tererosi daripada HPMC K15M sehingga gas dari komponen effervecent cepat hilang karena kurang terperangkap dalam matriks.

\section{Kemampuan mengembang}

Hasil pengujian swelling tablet floating verapamil $\mathrm{HCl}$ menghasilkan indeks swelling pada menit ke-360 sebesar 13 sampai $127 \%$ dengan persamaan $\mathrm{Y}=7,96+1,23 \mathrm{~A}$ $+2,59 \mathrm{~B}-0,62 \mathrm{AB}$. Hasil koefisien regresi menunjukkan bahwa faktor HPMC K15M (2,59) memberikan pengaruh pada peningkatan indeks swelling lebih besar daripada faktor pektin $(1,23)$, karena viskositas HPMC K15M lebih besar dari pektin. Interaksi kedua faktor memberikan pengaruh pada penurunan indeks swelling $(-0,62)$ karena adanya perbedaan sifat antara dua faktor tersebut. HPMC memiliki viskositas yang lebih kental sehingga tahan terhadap erosi sedangkan pektin viskositasnya lebih kecil dan semakin lama dapat tererosi. Swelling dari matriks akan mempengaruhi jumlah pelepasan obat dan kemampuan mengapung. 


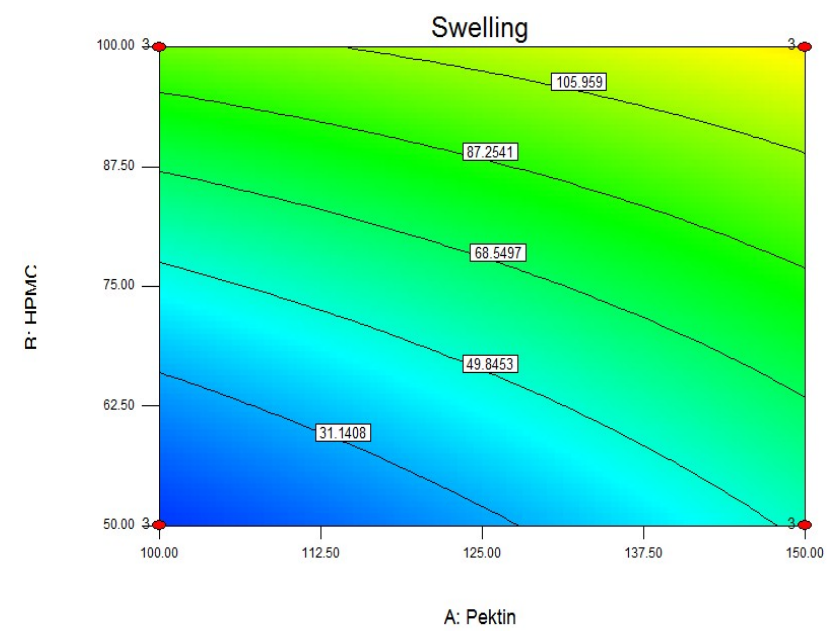

Gambar 3. Contour plot kemampuan mengembang

\section{Disolusi tablet floating verapamil $\mathrm{HCl}$}

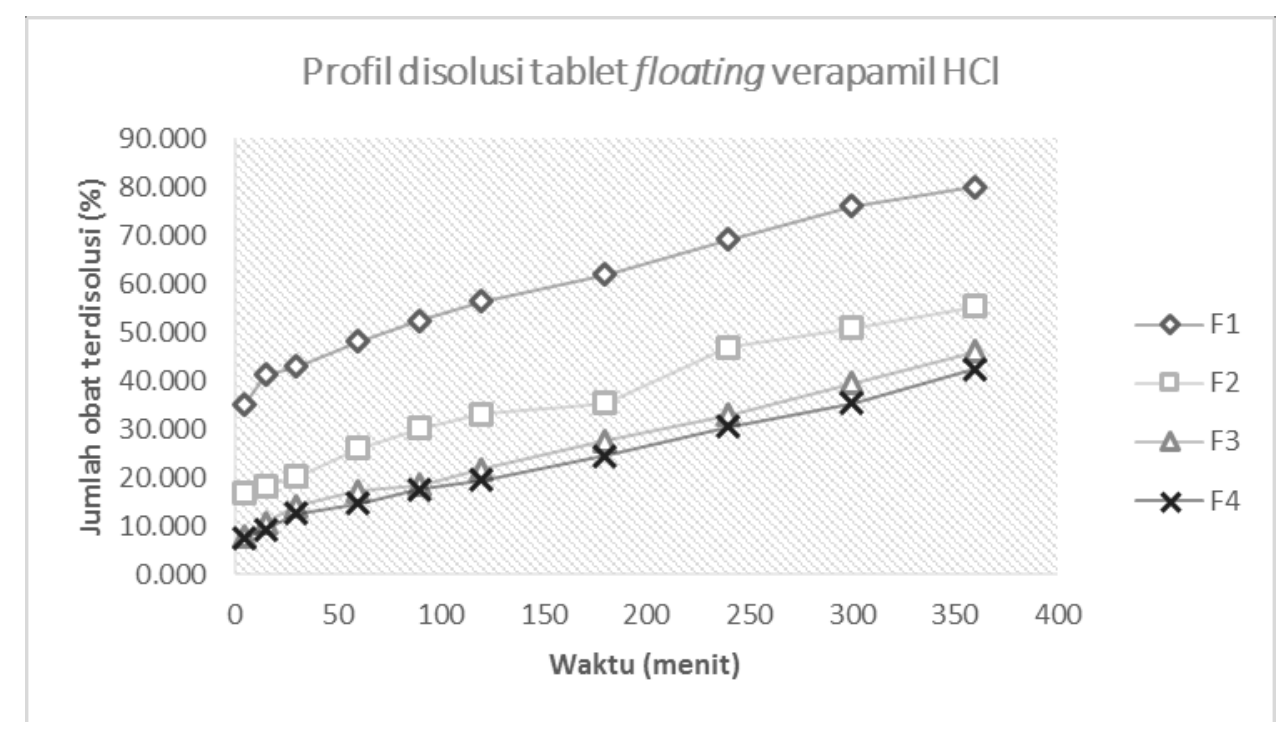

Gambar 4. Profil

disolusi

Profil disolusi dari tablet floating verapamil $\mathrm{HCl}$ dari kurva antara plot jumah obat terdisolusi dengan waktu menunjukkan bahwa keempat formula tersebut menunjukkan pola pelepasan yang sama. Hasil pemeriksaan disolusi menunjukkan peningkatan pektin dan HPMC K15M dapat menyebabkan penurunan pelepasan obat. Pektin dan HPMC K15M membentuk lapisan gel yang kuat dan mengalami pembengkakan sehingga obat akan terhalang lepas dari matriks. 
Tabel IV. Persentase jumlah obat yang terlepas pada tablet floating verapamil HCl

\begin{tabular}{|c|c|c|c|c|}
\hline \multirow{2}{*}{$\begin{array}{l}\text { Waktu } \\
\text { (menit) }\end{array}$} & \multicolumn{4}{|c|}{ Rata-rata terdisolusi (\%) } \\
\hline & $\mathrm{F} 1$ & $\mathrm{~F} 2$ & F3 & $\mathrm{F} 4$ \\
\hline 5 & 35,167 & 16,710 & 7,913 & 7,683 \\
\hline 15 & 41,237 & 18,275 & 10,679 & 9,389 \\
\hline 30 & 42,947 & 20,279 & 14,114 & 12,703 \\
\hline 60 & 48,132 & 26,150 & 17,304 & 14,715 \\
\hline 90 & 52,448 & 30,221 & 18,548 & 17,625 \\
\hline 120 & 56,469 & 33,075 & 21,753 & 19,496 \\
\hline 180 & 61,835 & 35,443 & 27,610 & 24,551 \\
\hline 240 & 69,207 & 46,910 & 32,950 & 30,611 \\
\hline \multirow[t]{2}{*}{300} & 76,014 & 50,920 & 39,521 & 35,339 \\
\hline & 79,933 & 55,305 & 46,114 & 42,491 \\
\hline DE60 & 41,125 & 20,038 & 12,833 & 11,359 \\
\hline DE360 & 61,459 & 37,903 & 27,648 & 25,037 \\
\hline
\end{tabular}
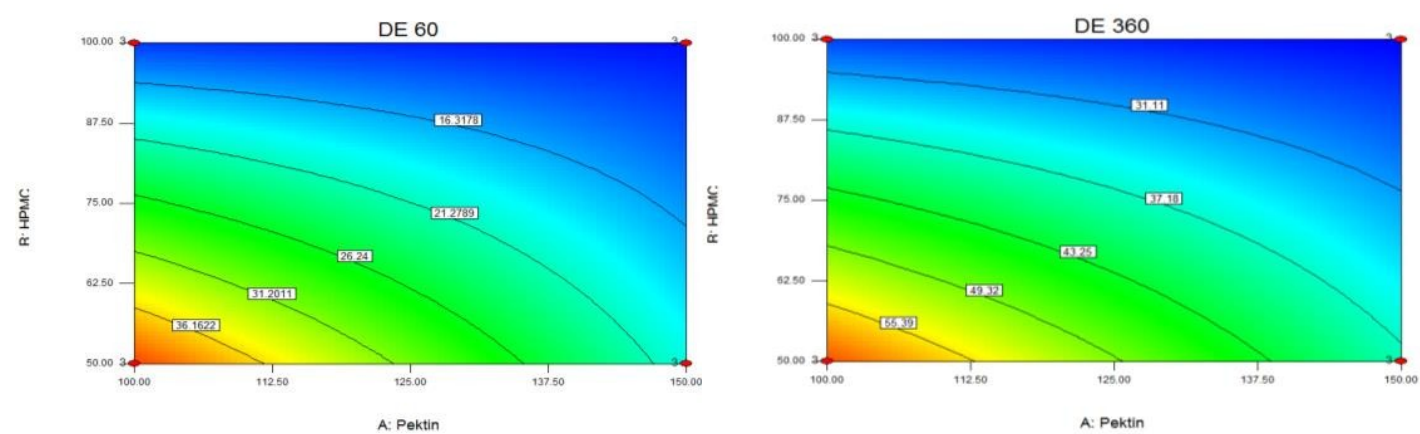

Gambar 5. Contour

plot $\mathrm{DE}$

Profil pelepasan obat yang lebih lambat dapat ditunjukkan dengan nilai DE yang lebih kecil. Hasil pemeriksaan DE60 didapatkan persamaan $\mathrm{Y}=21,34-5,64 \mathrm{~A}$ - 9,24 B + 4,90 AB. Hasil koefisien regresi menunjukkan bahwa faktor HPMC K15M $(-9,24)$ memberikan pengaruh pada penurunan DE60 lebih besar daripada faktor pektin $(-5,64)$. Interaksi faktor HPMC K15M dan faktor pektin $(4,90)$ dapat meningkatkan DE60. Sifat pektin yang lebih mudah tererosi daripada HPMC K15M menyebabkan penurunan DE60 lebih kecil dibandingkan HPMC K15M.
Hasil pemeriksaan DE360 didapatkan persamaan $\mathrm{Y}=38,01-6,54 \mathrm{~A}-11,67 \mathrm{~B}$ + 5,24 AB.

Hasil koefisien regresi menunjukkan bahwa faktor HPMC K15M $(-11,67)$ memberikan pengaruh pada penurunan DE360 lebih besar daripada faktor pektin (-6,54). Interaksi faktor HPMC K15M dan faktor pektin $(5,24)$ dapat meningkatkan DE360. Viskositas matriks yang kecil membentuk lapisan gel di sekitar tablet yang tipis sehingga obat lebih cepat terdifusi sehingga meningkatkan DE. 

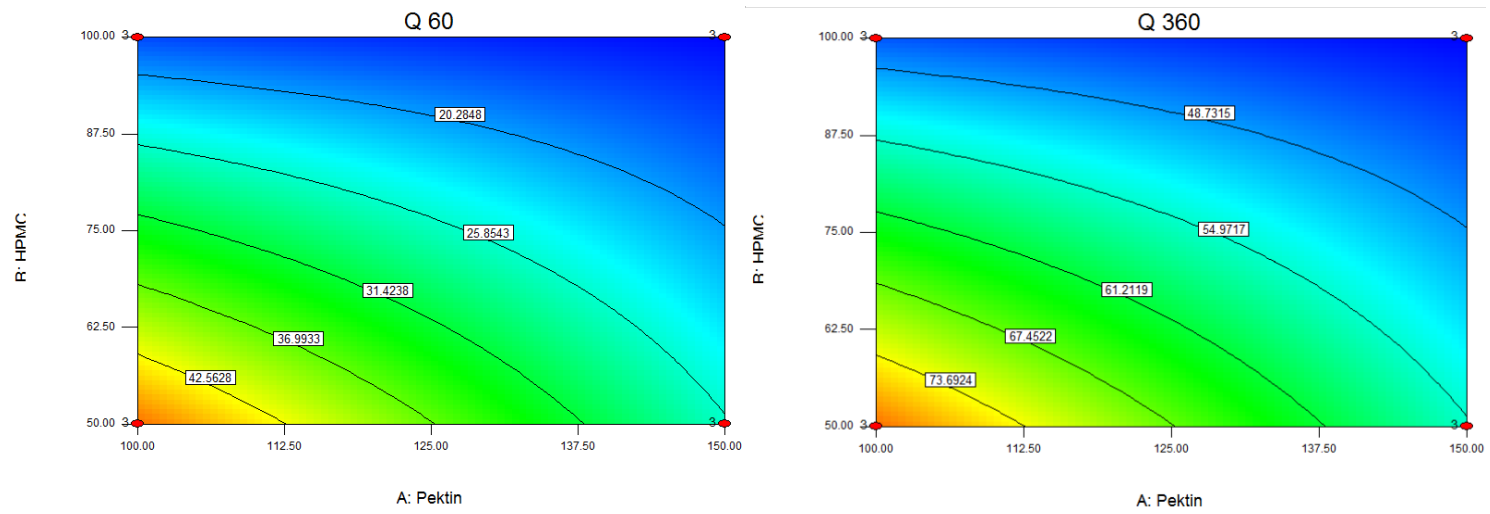

Gambar 5. Contour plot Q

Hasil pemeriksaan Q60 didapatkan persamaan $\mathrm{Y}=26,58-6,14 \mathrm{~A}-10,57 \mathrm{~B}+$ 4,85 AB. Hasil koefisien regresi menunjukkan bahwa faktor HPMC K15M (-10,57) memberikan pengaruh pada penurunan Q60 lebih besar daripada faktor pektin $(-6,14)$. Interaksi faktor HPMC K15M dan faktor pektin $(4,85)$ dapat meningkatkan Q60. Hasil pemeriksaan Q360 didapatkan persamaan $\mathrm{Y}=$ 55,96 - 7,06 A - 11,66 B + 5,25 AB. Hasil koefisien regresi menunjukkan bahwa faktor HPMC K15M $(-11,66)$ memberikan pengaruh pada penurunan Q360 lebih besar daripada faktor pektin $(-7,06)$,. Interaksi faktor HPMC K15M dan faktor pektin $(5,25)$ dapat meningkatkan Q360. Pektin lebih cepat mengembang di awal pada media asam daripada HPMC K15M, sehingga semakin lama pektin kurang mampu menahan pelepasan obat karena mengalami erosi. Pektin lebih bersifat hidrofilik daripada HPMC K15M sehingga pektin lebih cepat mengalami hidrasi.

Tabel V. Kinetika dan mekanisme pelepasan obat

\begin{tabular}{|c|c|c|c|c|c|}
\hline \multirow[t]{2}{*}{ Formula } & \multicolumn{5}{|c|}{ Pelepasan obat/ $\mathrm{R}^{2}$} \\
\hline & $\mathrm{Q}_{360}(\%)$ & Orde nol & Orde satu & Higuchi & Koersme peppas \\
\hline F1 & 79,933 & 0,977 & 0,933 & 0,991 & 0,994 \\
\hline $\mathrm{F} 2$ & 55,305 & 0,980 & 0,926 & 0,974 & 0,988 \\
\hline $\mathrm{F} 3$ & 46,114 & 0,993 & 0,921 & 0,964 & 0,985 \\
\hline F4 & 42,491 & 0,995 & 0,927 & 0,960 & 0,992 \\
\hline
\end{tabular}

Tabel 6. Mekanisme pelepasan obat dengan Korsmeyer-peppas

\begin{tabular}{llll}
\hline Formula & $\mathrm{R}^{2}$ & $\mathrm{n}$ & Mekanisme transport obat \\
\hline F1 & 0,994 & 0,736 & Difusi dan erosi \\
\hline F2 & 0,988 & 0,669 & Difusi dan erosi \\
\hline F3 & 0,985 & 0,634 & Difusi dan erosi \\
\hline F4 & 0,992 & 0,620 & Difusi dan erosi \\
\hline
\end{tabular}

Formula 4 lebih dominan mengikuti orde nol sehingga kecepatan pelepasannya konstan karena matriks lebih bisa menahan pelepasan obat. Formula 1 lebih dominan mengikuti model Higuchi yang membentuk pelepasan yang linear dengan fungsi akar waktu dan jumlah obat yang terdisolusi. Lapisan gel yang terbentuk pada tablet formula 1 kurang tebal dan mudah tererosi sehingga obat lebih mudah berdifusi.

Mekanisme pelepasan verapamil $\mathrm{HCl}$ dari sediaan tablet floating pada semua formula 
merujuk pada mekanisme anomalous transport atau Non-Fickian transport dengan mekanisme pelepasan obat secara difusi dan erosi, karena nilai eksponen (n) antara 0,45 sampai 0,89 . HPMC K15M merupakan matriks yang mengontrol pelepasan obat melalui difusi yang lebih tahan erosi sedangkan pektin mampu mengontrol pelepasan obat melalui difusi dan erosi.

\section{Simpulan}

Faktor HPMC K15M berpengaruh dominan terhadap floating lag time yang lebih cepat dan floating time yang lebih lama. Peningkatan aras faktor HPMC K15M dan pektin menurunkan jumlah pelepasan di awal dan kecepatan pelepasan obat, serta meningkatkan kemampuan mengembang. Interaksi antara faktor HPMC K15M dan pektin dapat meningkatkan floating lag time dan pelepasan obat serta menurunkan floating time dan kemampuan mengembang. Faktor pektin aras tinggi dan faktor HPMC K15M aras tinggi (1,5: 1) memiliki floating lag time paling cepat, floating time paling lama dan mampu mengembang paling besar dan mengikuti orde nol.

Perlu dilakukan optimasi untuk mengetahui formula optimum dari kombinasi matriks pektin dan HPMC K15M pada tablet floating verapamil $\mathrm{HCl}$ dengan metode factorial design dan penelitian lebih lanjut mengenai matriks pektin yang dapat dikombinasikan dengan HPMC jenis lain yang mempunyai pengaruh yang lebih efektif terhadap pelepasan obat pada tablet floating verapamil $\mathrm{HCl}$.

\section{Ucapan Terima Kasih}

Terima kasih kepada PT. Dexa medica yang telah memberikan HPMC K15M dan terima kasih kepada PT. Interbat yang telah memberikan Avicel PH-102 sebagai bahan penelitian

\section{Daftar Pustaka}

Abed HN, Abdulrasool AA, Ghareeb MM. 2011. Controlled Release Floating Matrix Tablet of Captopril. Iraqi J Pharm Sci. 20(2) : 1-8.

Gandjar IG, Rohman A. 2012. Kimia Farmasi Analisis. Yogyakarta : Pustaka Pelajar. Hlm.466-497.
Kadajji VG dan Betageri GV. 2011. Water Soluble Polymers for Pharmaceutical Applications: a review. Polymers. Department of Pharmaceutical Sciences, Western University of Health Sciences, Pomona. 3 : 1972- 2009.

Kilicarslan, M., dan Tamer, B. 2003. The effect of the drug/polymer ratio on the properties of the verapamil $\mathrm{HCl}$ loade microspheres. International Journal of Pharmecentics. 252:99-109.

Nikam et al. 2011. A novel gastro retentive controlled release drug delivery system of Verapamil Hydrochloride: Formulation and evaluation. JCPR. 3(2) : 932-939.

Siepmann J., Peppas NA. 2012. Modeling of drug release from delivery system based on hydroxypropyl methyl cellulose (HPMC). Adv. Drug Deliv. Rev. 48:139 - 157.

Sriamornsak P, Thriawong N, Weerapol Y, Nunthamid J, Sungthongjeen S. 2007. Swelling and erosion of pectin matrix tablets and their impact on drug release behavior. European Journal of Pharmaceutics and Biopharmacentics 67 : 211-219.

Sravya K, Kavitha K, Rupesh KM, Jagdeesh Sigh SD. 2012. Gastroretentive drug delivery systems: a review. Research Journal of Pharmaceutical, Biological and Chemical Sciences.3 (3) : 965 - 980.

48:139 - 157. 